OPEN ACCESS

Edited by:

Ross Houston,

University of Edinburgh,

United Kingdom

Reviewed by:

Shaojun Liu,

Hunan Normal University, China

Adelino V. M. Canario,

University of Algarve, Portugal

*Correspondence:

Scott F. Cummins

scummins@usc.edu.au

Specialty section

This article was submitted to

Livestock Genomics,

a section of the journal

Frontiers in Genetics

Received: 07 September 2018 Accepted: 28 January 2019

Published: 19 February 2019

Citation:

Chieu HD, Turner L, Smith MK,

Wang T, Nocillado J, Palma P.

Suwansa-ard $S$, Elizur $A$ and Cummins SF (2019) Aquaculture

Breeding Enhancement: Maturation and Spawning in Sea Cucumbers Using a Recombinant Relaxin-Like

Gonad-Stimulating Peptide.

Front. Genet. 10:77.

doi: 10.3389/fgene.2019.00077

\section{Aquaculture Breeding Enhancement: Maturation and Spawning in Sea Cucumbers Using a Recombinant Relaxin-Like Gonad-Stimulating Peptide}

\author{
Hoang Dinh Chieu ${ }^{1,2}$, Luke Turner ${ }^{3}$, Meaghan K. Smith ${ }^{1}$, Tianfang Wang ${ }^{1}$, \\ Josephine Nocillado ${ }^{1}$, Peter Palma ${ }^{1,4}$, Saowaros Suwansa-ard ${ }^{1}$, Abigail Elizur ${ }^{1}$ and \\ Scott F. Cummins ${ }^{1 *}$ \\ ${ }^{1}$ Genecology Research Centre, University of the Sunshine Coast, Sippy Downs, QLD, Australia, ${ }^{2}$ Research Institute for \\ Marine Fisheries, HaiPhong, Vietnam, ${ }^{3}$ Tasmanian Seafoods Pty. Ltd., Smithton, TAS, Australia, ${ }^{4}$ Aquaculture \\ Department, Southeast Asian Fisheries Development Center, Iloilo, Philippines
}

Wild sea cucumber resources have been rapidly exhausted and therefore there is an urgent need to develop approaches that will help restocking. Currently, there is a lack of information regarding the genes involved in sea cucumber reproductive processes. The neurohormone relaxin-like gonad-stimulating peptide (RGP) has been identified as the active gonad-stimulating peptide in sea stars (Asteroidea), which could also be present in other echinoderm groups. In this study, a sea cucumber RGP was identified and confirmed by phylogenetic analysis. A recombinant Holothuria scabra RGP was produced in the yeast Pichia pastoris and confirmed by mass spectrometry. To assess bioactivity, four levels of purification were tested in an in vitro germinal vesicle breakdown (GVBD) bioassay. The most pure form induced $98.56 \pm 1.19 \%$ GVBD in $H$. scabra and $89.57 \pm 1.19 \%$ GVBD in Holothuria leucospilota. Cruder levels of purification still resulted in some GVBD. Upon single injection into female $H$. scabra, the recombinant RGP induced head waving behavior followed by spawning within 90-170 min. Spawned oocytes were fertilized successfully, larvae settled and developed into juveniles. Our results provide a key finding for the development of a break-through new artificial breeding approach in sea cucumber aquaculture.

Keywords: aquaculture, juvenile, oocyte maturation, recombinant RGP, sea cucumbers, spawning

\section{INTRODUCTION}

Sea cucumbers are widely considered as commercially valuable with a high demand for consumption and use in some traditional medicines (Olivera-Castillo et al., 2013; Fahmy et al., 2015). As a result, many species have been critically overfished, which has led to the rapid exhaustion of wild populations (Lovatelli, 2004; Purcell et al., 2011). With reduced stocks, artificial breeding has become an effective solution to produce high quality seed for aquaculture, stock enhancement, and sea ranching. Spawning induction is a critical procedure in artificial breeding, however, traditional stimulation methods such as thermal shock, drying then rehydration, exposure 
to conspecific sperm, and a combination of the aforementioned treatments (Al Rashdi et al., 2012) are not efficient. In addition, traditional stimulation methods are thought to reduce the health of broodstock. As such, the employment of reproductive neuropeptide hormones for achieving reproductive maturation and spawning is an innovative approach with great potential to advance hatchery production in sea cucumber aquaculture.

In sea cucumbers, immature oocytes cannot be fertilized and insemination is only successful following germinal vesicle breakdown (GVBD), leading to the formation of the first and second polar bodies (Maruyama, 1980). Oocyte maturation and ovulation can be induced by a hormonal substance present within the radial nerve (Maruyama, 1980). Crude radial nerve extract (RNE) has been shown to stimulate maturation of fully grown oocytes within various sea cucumber species, including Holothuria leucospilota, Holothuria pervicax, Holothuria moebi, Holothuria pardalis, and Apostichopus japonicus (Maruyama, 1980, 1985; Katow et al., 2009). Meanwhile, several peptide hormones have been recognized as inducers of oocyte maturation in sea cucumbers, including the gonad-stimulating substancelike molecule (GSSL), cubifrin (NGIWYamide, NGLWYamide), and the heptapeptide QGLFSGVamide (Kato et al., 2009; Katow et al., 2009; Leonet et al., 2009; Fujiwara et al., 2010; Yamano et al., 2013).

GSSL is a $4.8 \mathrm{kDa}$ single chain peptide which was isolated from the radial nerve of $A$. japonicus. A synthetic GSSL peptide, at $6 \mu \mathrm{M}$, was capable of inducing GVBD at $50 \%$ efficiency (Katow et al., 2009). The neuropeptide cubifrin-I (NGIWYamide) and its derivative cubifrin-L (NGLWYamide) have been reported as potent inducers of in vitro oocyte maturation and spawning in A. japonicus (Kato et al., 2009; Fujiwara et al., 2010; Yamano et al., 2013). However, cubifrin may not be effective for all sea cucumber species, where for example, synthetic cubifrin could not induce oocyte maturation in $H$. leucospilota at concentrations from $1 \mathrm{nM}$ to $10 \mu \mathrm{M}$ (Chieu et al., 2018). Meanwhile, a second synthesized peptide, QGLFSGVamide could induce GVBD at concentrations $\geq 1 \mu \mathrm{M}$ (Kato et al., 2009). However, due to its low potency, this peptide was not suggested as the primary endocrine regulator of oocyte maturation and therefore was not considered for further study (Kato et al., 2009). Lastly, MIF (maturation inducing fractions) collected by gel filtration chromatography from spawned egg extract of the regular sea urchins (e.g., Echinometra mathaei, Stomopneustes variolaris, Paracentrotus lividus) could also induce oocyte maturation and spawning in the sea cucumber (Leonet et al., 2009). The bioactive peptide sequences of MIF are still unknown.

The relaxin-like gonad-stimulating peptide (RGP), originally denoted as GSS (gonad-stimulating substance) in the sea stars due to its classification as a member of the relaxin superfamily, is suggested as the first identified invertebrate gonadotropin to trigger final gamete maturation (Mita et al., 2009; Mita, 2013, 2016). The neuroendocrine mechanism involved in endogenous regulation of oocyte maturation and spawning is considered to be similar among other echinoderm groups, including the sea cucumbers (Smiley, 1990; Mercier et al., 2009). RGP is a heterodimer composed of two peptides (A- and B-chains) with disulphide cross-linkages and the A-chain harboring a cysteine motif "CCXXXCXXXXXXXXC", where "X" represents any other amino acid (Mita et al., 2009; Mita, 2013). Synthetic RGP (bonded) has been shown to induce oocyte maturation and ovulation within $30 \mathrm{~min}$ of incubation, however, no induction occurred when ovarian fragments were incubated with A- or Bchains alone, or as a mixture (unbonded) (Mita et al., 2009; Mita, 2013). As a result, the quaternary structure of RGP is necessary for hormonal action and this structure is complex and difficult to chemically synthesize. Instead of synthetic RGP, an effective approach to obtain RGP with correct quaternary structure is the production of a recombinant RGP in the methylotrophic yeast such as Hansenula polymorpha, Pichia pastoris, and Candida boidinii.

The methylotrophic yeast ( $P$. pastoris) has been developed as a high-level production system for recombinant proteins (Hollenberg and Gellissen, 1997), with several advantages such as rapid growth rate, high levels of productivity in an almost protein-free medium, ease of genetic manipulation of well-characterized yeast expression vectors and diverse post-translational modifications of disulphide bonds within the yeasts secretory pathway (Weinacker et al., 2013). Recombinant gonadotropin or gonad-stimulating hormone like peptides have been produced and studied in several aquatic species, such as a recombinant tilapia LH stimulated the release of 11-ketotestosterone from mature testes (Kasuto and LevaviSivan, 2005); a recombinant molt-inhibiting hormone-B (MeMIH-B) that could induce yolk protein synthesis in the shrimp (Metapenaeus ensis) (Tiu and Chan, 2007); induction of spermatogenesis in the eel Anguilla japonica by a recombinant goldfish (Carassius auratus) gonadotropins (Hayakawa et al., 2008); regulation of steroidogenesis and early ovarian development in juvenile grouper by a recombinant orangespotted grouper (Epinephelus coioides) follicle-stimulating hormone (FSH) (Chen et al., 2012); phosphorylation was elevated significantly in the testis of Eastern spiny lobster Sagmariasus verreauxi by a recombinant insulin-like androgenic gland hormone (Aizen et al., 2016); and in vitro and in vivo biological activities in oocyte development and spermatogenesis by a recombinant yellowtail kingfish (Seriola lalandi) FSH (Sanchis-Benlloch et al., 2017). However, production and biological activities of recombinant gonadotropin or gonadstimulating hormones/peptides have been poorly studied in invertebrates, especially in echinoderm species.

RGP has not been well studied in the sea cucumbers with the exception of the first identification of relaxin-like peptide-1 (gonad-stimulating substance type) genes reported in Holothuria scabra, Holothuria glaberrima and A. japonicus (Suwansa-ard et al., 2018). To date, the bioactive functions of RGP have not been verified in sea cucumbers. In this study, we have investigated the phylogeny of sea cucumber RGPs with other echinoderm species relaxin-like peptides. A recombinant $H$. scabra RGP was generated in the $P$. pastoris yeast expression system and subsequently confirmed by mass spectrometry. The recombinant RGP, when injected, induced oocyte maturation and spawning and the spawned oocytes were successfully fertilized leading to larvae and juvenile development. 


\section{MATERIALS AND METHODS}

\section{RGP Annotation and Comparative Sequence Analysis}

Transcripts encoding echinoderm RGP were obtained by tBLASTn search using the H. scabra RGP (Suwansa-ard et al., 2018) as a query. The deduced amino acid sequence of $H$. leucospilota RGP was analyzed for the presence of a signal peptide by using the SignalP 4.1 (Petersen et al., 2011). Proteomic cleavage sites and post-translational modifications of the RGP precursor peptide were predicted by NeuroPred (Southey et al., 2006). Amino acid alignment of echinoderm RGP was performed by MEGA 7 software (Kumar et al., 2016) and subsequently illustrated by using MikTex Texshade software. Phylogenetic tree analysis of echinoderm RGP based on maximum likelihood estimation was conducted using the Phylogeny.fr webserver (http://www.phylogeny.fr). The tree was constructed by using the amino acid sequences of mature RGP A- and B-chain peptides with the inter-chain region, along with its evolutionaryrelated peptide, the insulin-like growth factor (IGF), which was used as an outgroup. The parameters were set as follows: substitution model, WAG; gamma, 2.5; Number of substitution rate categories, 4; number of bootstraps, 500 .

\section{Construction and Transformation of RGP Recombinant Plasmid}

A $H$. scabra RGP construct was designed with a histidine linker positioned between chain A and chain B (Figure 1). Following synthesis and insertion of the RGP gene into pPIC9K vector (Genscript Biotech Company), it was transformed into JM109 competent cells (Promega Corporation). Recombinant plasmid RGP-pPIC9K was then purified using the GeneJET plasmid Midiprep Kit (Thermo Scientific) and digested with Sal I (Thermo Scientific) using a standard approach, before being transformed into the yeast $P$. pastoris (strain SuperMan5, phenotype $\mathrm{His}^{-}$, Biogrammatics) following a standard electroporation protocol (Madden et al., 2015). Transformed yeast cells were grown on RDB (regeneration dextrose medium) plates for 4 days at $30^{\circ} \mathrm{C}$. After that, colonies were transferred to 96 -well culture plates containing $200 \mu$ l yeast extract:peptone:dextrose (YPD) solution/well supplemented with different concentrations of Geneticin selective antibiotic (G418 disulfate, MERCK), including at 0,1 , and $2 \mathrm{mg} / \mathrm{mL}$, respectively. After growing at $30^{\circ} \mathrm{C}$ for $1-2$ days, RGP colony growth was determined at $\mathrm{OD}_{600}$ using a Multimode plate Reader (EnSpire 2300, Perkin Elmer).

\section{Induction of Recombinant Protein Expression}

Yeast containing recombinant RGP plasmid with high expression levels were inoculated into a $200 \mathrm{~mL}$ YPD solution, at $28^{\circ} \mathrm{C}$. After $24 \mathrm{~h}$, yeast cells were collected by centrifugation at 3,000 $\mathrm{x} \mathrm{g}$, for $5 \mathrm{~min}$ and subsequently resuspended in $400 \mathrm{~mL}$ BMG (buffered minimal glycerol) medium and grown for $24 \mathrm{~h}$, at $28^{\circ} \mathrm{C}$, until an $\mathrm{OD}_{600}>1$. Then, cells were pelleted by centrifugation $\left(3,000 \times \mathrm{g}\right.$, for $5 \mathrm{~min}$ at $\left.28^{\circ} \mathrm{C}\right)$ and resuspended in $\mathrm{BMM}$ (buffered minimal methanol) medium. After 3 days, cells were collected by centrifugation $\left(3,000 \times \mathrm{g}\right.$, for $10 \mathrm{~min}$ at $\left.4^{\circ} \mathrm{C}\right)$. The supernatant was taken for secreted protein analysis. For negative controls, yeast cells containing no recombinant plasmid were grown as described and the supernatant collected for secreted protein analysis.

\section{Recombinant RGP Purification}

Recombinant RGP was purified to 4 levels:

(1) Crude RGP supernatant (CS): supernatant was collected by centrifugation $\left(3,000 \mathrm{xg}\right.$, for $10 \mathrm{~min}$ at $4^{\circ} \mathrm{C}$ ) after growing yeast in BMM solution for 3 days.

(2) Crude concentrated RGP (CR): CS was immediately frozen in liquid nitrogen, and then lyophilized by freeze-drying (model ModulyoD, Thermo Fisher).

(3) C18 SepPak-purified RGP (SR): CS was purified through C18 SepPak cartridge (Waters Corporation) following the manufacturer's instruction.

(4) His and Amicon-purified RGP (HR): CS was treated using a Ni-NTA superflow (QIArack kit, QIAGEN) under native conditions. Imidazole was removed from elution fractions using an Amicon Ultra-15 centrifugal filter device with a 3 KDa cut-off (MERCK). All purification steps followed the manufacturers guidelines.

Protein concentration was determined using a Nanodrop 2000 (Thermo Scientific, Wilmington, DE, USA). All preparations were kept at $-80^{\circ} \mathrm{C}$ before used in mass spectrometry analysis and bioassays.

\section{uHPLC Tandem QTOF MS/MS Analyses of Recombinant RGP}

His and Amicon-purified RGP was digested by trypsin (Promega) in-solution using the method described previously ( $\mathrm{Ni}$ et al., 2018). Then, trypsin-digested peptide solutions were adjusted to $\mathrm{pH}<3$ by adding $10 \%$ formic acid and analyzed by LC-MS/MS on an ExionLC liquid chromatography system (AB SCIEX) coupled to a QTOF X500R mass spectrometer (AB SCIEX) equipped with an electrospray ion source. Twenty microliters of each sample were injected onto an Aeris ${ }^{\mathrm{TM}} 1.7 \mu \mathrm{m}$ PEPTIDE XB-C18 100 $\AA$ uHPLC column (Phenomenex, Sydney, Australia) equipped with a SecurityGuard column for mass spectrometry analysis. For mobile phases, solvent A consisted of $0.1 \%(\mathrm{v} / \mathrm{v})$ formic acid and solvent B contained $100 \%$ acetonitrile/ $0.1 \%$ formic acid. Linear gradients of $5-35 \%$ solvent B over $10 \mathrm{~min}$ at $400 \mu \mathrm{L} / \mathrm{min}$ flow rate, followed by a steeper gradient from 35 to $80 \%$ solvent B in 2 min and 80 to $95 \%$ solvent B in 1 min were used for peptide elution. Solvent B was held at $95 \%$ for $1 \mathrm{~min}$ for washing the column and returned to $5 \%$ solvent $\mathrm{B}$ for equilibration prior to the next sample injection. The ionspray voltage was set to $5500 \mathrm{~V}$, declustering potential $100 \mathrm{~V}$, curtain gas flow 30, ion source gas 140 , ion source gas 2 (GS2) 50 and spray temperature at $450^{\circ} \mathrm{C}$. The mass spectrometer acquired mass spectral data in an Information Dependant Acquisition, IDA mode. Full scan TOF-MS data was acquired over the mass range 350-1,400 and for product ion $\mathrm{ms} / \mathrm{ms} 50-1,800$. Ions observed in the TOF-MS scan exceeding a threshold of $100 \mathrm{cps}$ and a charge state of +2 to +5 were set to trigger the acquisition of product ion. The 


\section{B-chain

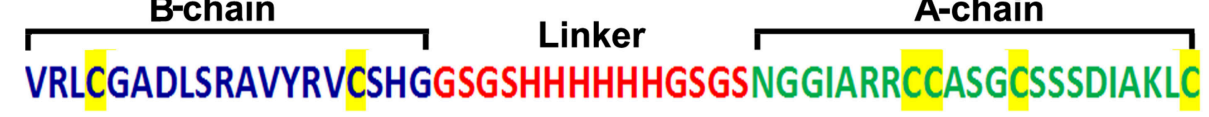

FIGURE 1 | Holothuria scabra RGP protein encoded within the vector construct. A-Chain (green), B-chain (Blue) and histidine linker (red) regions are shown. Yellow highlight backgrounds indicate conserved cysteine residues.

data was acquired and processed using SCIEX OS software (AB SCIEX, Concord, Canada). Biological triplicates were used for the analysis.

LC-MS/MS data was imported into the PEAKS studio (Bioinformatics Solutions Inc., version 7.0) with the assistance of MS Data Converter (Beta 1.3, http://sciex.com/ software-downloads-x2110). De novo sequencing of peptides, database search and characterizing specific post translational modifications (PTMs) were used to analyse the raw data; false discovery rate was set to $\leq 1 \%$, and $\left[-10^{*} \log (\mathrm{p})\right]$ was calculated accordingly where $\mathrm{p}$ is the probability that an observed match is a random event. The PEAKS used the following parameters: (i) precursor ion mass tolerance, $0.1 \mathrm{Da}$; (ii) fragment ion mass tolerance, $0.1 \mathrm{Da}$; (iii) tryptic enzyme specificity with two missed cleavages allowed; (iv) monoisotopic precursor mass and fragment ion mass; (v) a fixed modification of cysteine carbamidomethylation; and (vi) variable modifications including lysine acetylation, deamidation on asparagine and glutamine, oxidation of methionine and conversion of glutamic acid and glutamine to pyroglutamate.

\section{Structure Prediction of Recombinant RGP Using Molecular Dynamic Simulation}

The initial conformations of recombinant RGP were built as a linear structure using the LEAP module of AMBER 14 (Case et al., 2014). Molecular dynamic (MD) simulation was fully unrestrained and carried out in the canonical ensemble using the SANDER module. The ff14SB force field (Duan et al., 2003) was employed. Energy minimization with 2500 steps was first performed to remove unfavorable contacts. The AMBER structure was then heated to $325 \mathrm{~K}$ over 50 ps to avoid being kinetically trapped in local minima, then subjected to unrestrained MD simulations at $325 \mathrm{~K}$ for the purpose of peptide equilibration. The structural information was sampled every 1 ps (i.e., 10,000 structures were calculated for $10 \mathrm{~ns}$ MD simulation). This MD simulation was continued until the root mean square deviation of structures within a reasonable long time range was stable at/less than $3 \sim 4 \AA$. Then a lowest energy structure was determined and considered as the representative of the conformations simulated over this period. Visualization of the systems was effected using VMD software (Humphrey et al., 1996).

\section{Germinal Vesicle Breakdown and Spawning Bioassay Using Recombinant RGP}

Adult female H. scabra (300 $\pm 50 \mathrm{~g}$ in body weight) were obtained from a broodstock population at a commercial aquaculture facility within the Darwin Aquaculture Center (Northern Territory, Australia). Adult female H. leucospilota (250 $\pm 50 \mathrm{~g}$ in body weight) based on biopsy via a small incision at the dorsal bivium, were collected from Point Cartwright (Mooloolaba, Australia) and housed in an protein skimmed saltwater aquarium system at the University of the Sunshine Coast (Sippy Downs, Australia).

For the in vitro GVBD bioassay, ovarian tubules were dissected from individuals of $H$. scabra and $H$. leucospilota at gonad stage III (advanced mature, oocyte diameter $>150 \mu \mathrm{m}$ ). Ovarian tubules were cut transversely into $\sim 5 \mathrm{~mm}$ long sections and transferred into 96-well microplates containing $80 \mu \mathrm{L}$ of filtered artificial sea water (FASW) and different RGP extracts, including $\mathrm{CS}, \mathrm{CR}, \mathrm{SR}$ and $\mathrm{HR}$, at various concentrations as follows: $1.75-7.00 \mu \mathrm{g} / \mu \mathrm{L}$ of CS; $28.25-113.00 \mu \mathrm{g} / \mu \mathrm{L}$ of $\mathrm{CR}$; $24.00-96.00 \mu \mathrm{g} / \mu \mathrm{L}$ of SR; and $0.004-0.016 \mu \mathrm{g} / \mu \mathrm{L}$ of HR. Yeast supernatant containing no recombinant plasmid was used as a negative control, while $0.2 \mu \mathrm{g} / \mu \mathrm{L}$ RNE prepared as described in our previous study (Chieu et al., 2018) was used as a positive control. Each test sample was performed in triplicate. Ovarian tubules were incubated in the test media at $24^{\circ} \mathrm{C}$ for $3 \mathrm{~h}$ and then released oocytes and in-tubule oocytes identified under a stereomicroscope (Nikon SMZ800N, Nikon). Observations were taken regularly during this period. The total number of mature and immature oocytes was recorded based on presence or absence of the germinal vesicle and recorded as a percentage.

For the in vivo spawning bioassay, CS and HR were tested for $H$. scabra behavior changes and induction of spawning. Two negative controls, including filtered artificial seawater (FASW) and yeast supernatant without RGP (YR), were also included. Twelve sea cucumbers (ca. $250 \mathrm{~g}$ in total body weight/animal), 3 for each test sample, were kept separately in $5 \mathrm{~L}$ seawater. Test samples were injected into the body wall. The injection schedule and concentrations for each test sample is shown in Table 1. Animal behavior, specifically head waving (where the anterior region sways from side to side at the surface of the seawater) that is a typical behavior for sea cucumbers prior to spawning and spawning were recorded using time-lapse (HD webcam 720p, Logitech) for $1.5 \mathrm{~h}$ and if no spawning was observed, a second injection was performed.

Spawned oocytes were collected for fertilization with spermatozoa aspirated from a mature $H$. scabra using a hypodermic needle and syringe. The spermatozoa were suspended in $50 \mathrm{~mL}$ seawater, from there, a few drops of sperm solution were added to containers with mature oocytes. After $30 \mathrm{~min}$, fertilized ova were collected by filtering using a $60 \mu \mathrm{m}$ mesh screen and the excess spermatozoa removed by rinsing with seawater. Fertilized ova were hatched in 1,000 L tanks and 
TABLE 1 | Schedule and concentration for the tested sample injections into female Holothuria scabra.

\begin{tabular}{lcc}
\hline Test sample & $\begin{array}{c}\text { 1st injection (2 } \mathbf{~ L}) \\
\text { (mg peptide/animal) }\end{array}$ & $\begin{array}{c}\text { 2nd injection (3 mL) } \\
\text { (mg peptide/animal) }\end{array}$ \\
\hline $\begin{array}{l}\text { Crude RGP supernatant } \\
\text { (CS) }\end{array}$ & 14 & 21 \\
His and Amicon-purified & 0.040 & NA \\
RGP (HR) & 0 & 0 \\
$\begin{array}{l}\text { Filtered artificial seawater } \\
\text { (FASW) }\end{array}$ & 0 & 0 \\
Yeast supernatant without & 0 & \\
RGP (YR) & & \\
\hline
\end{tabular}

transferred into 5,000 L rearing tanks at 2 days post-fertilization. The larvae were fed daily with live diatoms until reaching juvenile stage.

\section{RESULTS}

\section{Comparative Analysis of Echinoderm RGPs and IGFs}

Echinoderm RGP transcripts present within the NCBI databases were obtained, including a single transcript encoding RGP peptide precursor deduced from H. leucospilota (Supplementary Data S1). The H. leucospilota RGP peptide precursor is composed of 123 amino acid residues, which includes a 25 amino acid signal peptide sequence and a 98 amino acid RGP propeptide that contains two predicted A- and B-chain RGP peptides. The A-chain peptide, located at the $\mathrm{C}$-terminus of the RGP propeptide, is 22 residues in length, while the B-chain peptide, located at the N-terminus of the RGP propeptide, is 19 residues in length and includes a C-terminal glycine residue (predicted to be an amide donor for C-terminal amidation). Both A- and B-chain peptides contain highly conserved cysteine residues that are known to be essential for disulphide bridge formation.

A comparative amino acid alignment of echinoderm RGPs/IGFs was performed (Figure 2A). H. leucospilota RGP shows the highest similarity in its amino acid composition to the H. glaberrima RGP (87.8\% identity) and, with a lesser extent, the H. scabra RGP (86.99\%). However, H. leucospilota RGP shows only $49.59 \%$ identity to the sea cucumber A. japonicus. Although RGPs and IGFs share the conservation of amino acid residues within the $\mathrm{A}$ - and $\mathrm{B}$-chain regions, especially the conserved cysteine residues which are potentially important for disulphide bridge formation (asterisks, Figure 2A), variable amino acids were observed throughout the mature peptide length. Noteworthy, the glycine residues located prior to the third conserved cysteine residue of the A-chains were present in RGPs but not in IGFs (arrow, Figure 2A). Phylogenetic tree analysis of echinoderm RGPs showed a distinct clade of the echinoderm RGPs, separated from the echinoderm IGFs (Figure 2B). Two major clades (with 95\% bootstrap support) were observed within the RGP group, including sea cucumber RGPs and sea star RGPs, suggesting an evolutionary divergence in accordance with the divergence of holothuroids and asteroids.

\section{Production of a Recombinant $\boldsymbol{H}$. scabra RGP}

A H. scabra RGP-pPIC9K recombinant plasmid was successfully electro-transformed into the yeast cells and colonies were grown in different concentrations of Geneticin selective antibiotic $(0,1$, and $2 \mathrm{mg} / \mathrm{mL})$ at $30^{\circ} \mathrm{C}$ for 2 days. Those colonies that showed strong growth, even in high concentration of Geneticin (Supplementary Figure S1), were selected for largescale RGP production and purification. Mass spectrometry showed the presence of $H$. scabra RGP matching peptides with high confidence (Figure 3A, Supplementary Data S2). MD simulation was used to build a model for the recombinant H. scabra RGP and a properly folded 3D structure was obtained (Figure 3B); this model was supported by the relatively stable potential energy (Figure 3C, top) as well as backbone RMSD (root mean square deviation) during the same MD (Figure 3C, bottom).

\section{In vitro GVBD Bioassay}

Recombinant $H$. scabra RGP at four levels of purification was tested for induction of GVBD using ovarian tubules derived from adult $H$. scabra and H. leucospilota. Table 2 summarizes the results in both species. GVBD was observed at different efficiencies for the CS, SR and HR treatments, as well as for the positive control using $0.2 \mu \mathrm{g} / \mu \mathrm{L}$ RNE. CS at a concentration of $1.75-3.50 \mu \mathrm{g} / \mu \mathrm{L}$ induced GVBD at a relatively low efficiency (6.62-7.57\% in H. scabra and $0.34-1.39 \%$ in H. leucospilota), while at $7 \mu \mathrm{g} / \mu \mathrm{L}$, no GVBD occurred. Furthermore, oocytes showed a partial distortion at $3.5 \mu \mathrm{g} / \mu \mathrm{L}$ and complete distortion at $7 \mu \mathrm{g} / \mu \mathrm{L}$ (distortion is when oocyte shows a rough surface and deformed shape, which is an abnormal phenomenon that usually indicates stressed oocyte) (Figure 4A). CR did not stimulate oocyte GVBD, yet caused oocyte distortion at $56.5 \mu \mathrm{g} / \mu \mathrm{L}$, and complete distortion at $113 \mu \mathrm{g} / \mu \mathrm{L}$ (Figure 4B). GVBD was clearly observed in SR (Figure 4C) and HR (Figure 4D). For SR, almost $100 \%$ GVBD occurred at $96 \mu \mathrm{g} / \mu \mathrm{L}$, which was comparable to the treatment of $0.008 \mu \mathrm{g} / \mu \mathrm{L}$ HR. GVBD was observed in both released oocytes and in-tubule oocytes.

In the positive control group, $0.2 \mu \mathrm{g} / \mu \mathrm{L}$ RNE could induce $96.78 \%$ GVBD in H. scabra and $96.67 \%$ in $H$. leucospilota (Table 2). The oocytes showed extrusion from ovarian segments and matured in the RNE medium (Figure 4E). In negative controls, neither significant oocyte extrusion nor GVBD was occurred in YS and FASW treatments (Figures 4F,G). However, the YS caused oocyte distortion (Table 2).

\section{In vivo Spawning Bioassay, Fertilization, and Larval Development}

Based on results obtained from the GVBD bioassay, the CS and HR were tested in a spawning bioassay in H. scabra. As negative controls, FASW and yeast solution were tested. A summary of the results is shown in Figure 5. All animals used in the experiment had developing ovaries, as determined by biopsy (Figure 6A). This was most clear following biopsy and oocyte observation under a light microscope, showing immature oocytes at $\geq 150 \mu \mathrm{m}$ diameter (Figure 6B). After 
A

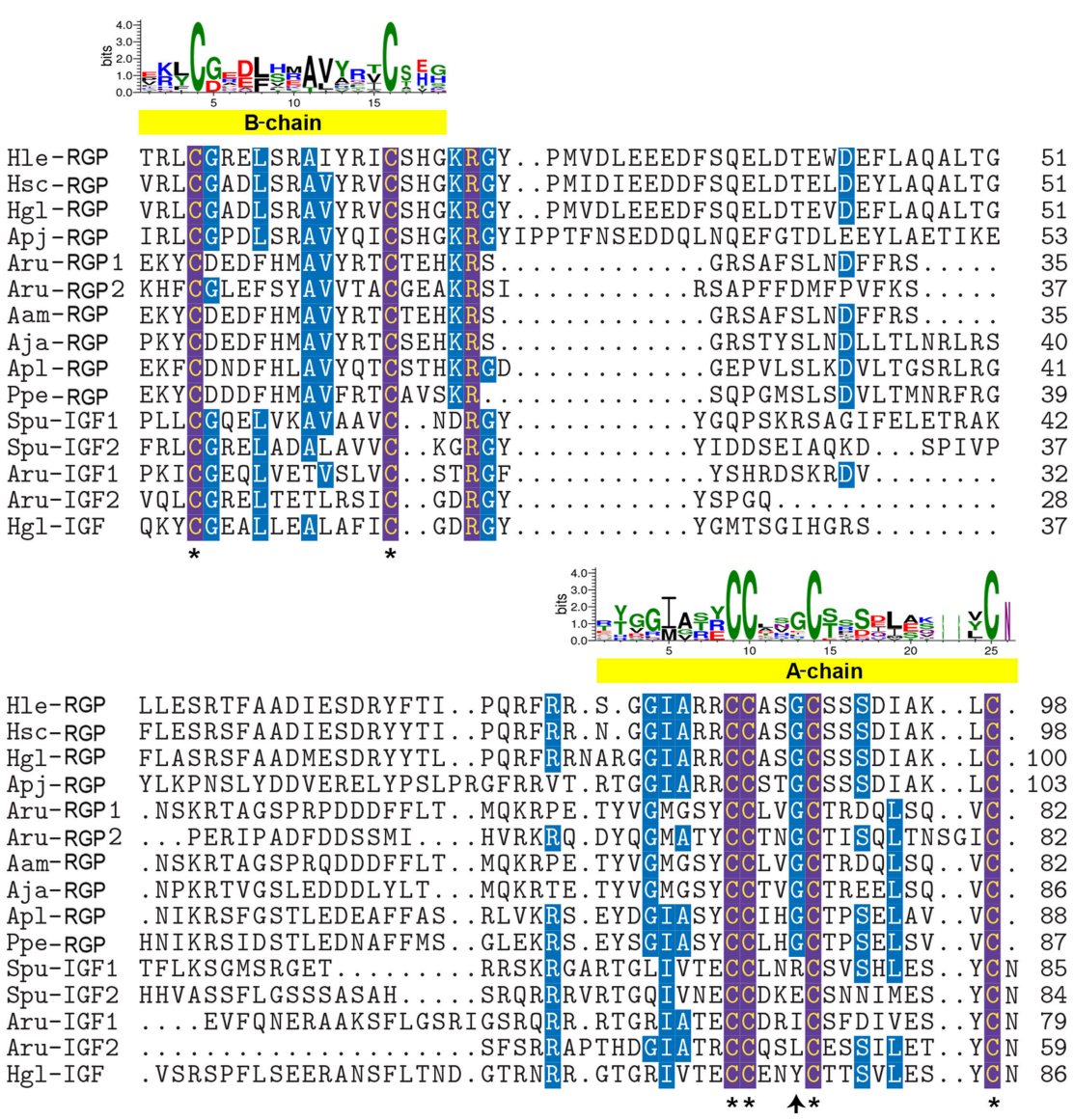

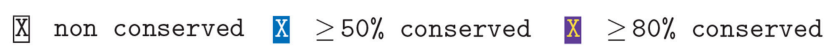

B

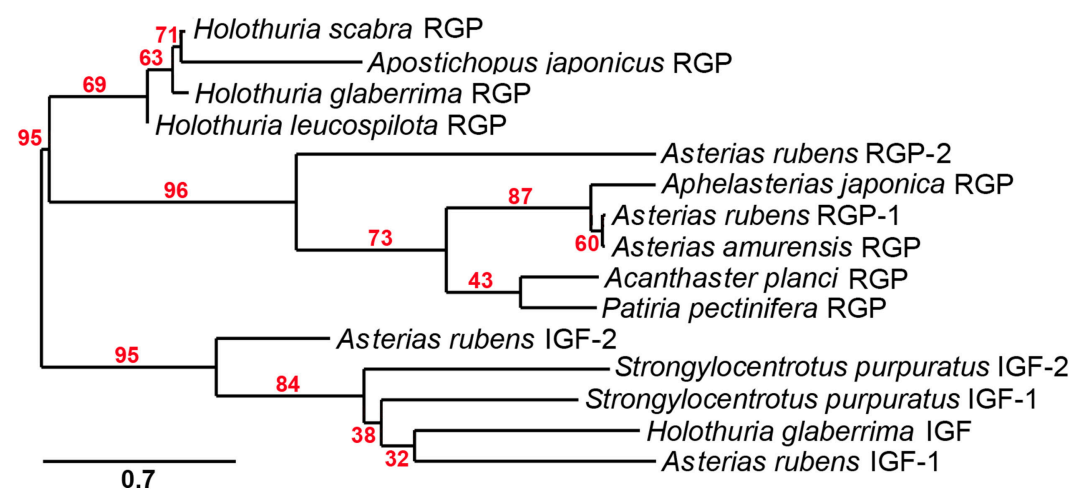

FIGURE 2 | Multiple sequence alignment and phylogenetic tree analysis of echinoderm RGP/IGF mature peptides. (A) Alignment of echinoderm RGP/IGF mature peptides. The yellow bars indicate the putative A- and B-chain peptides which contain the highly conserved cysteine residues (asterisks) important for disulphide bridge formation. The sequence logo above the alignment shows the conservation of amino acid composition at each position. (B) Phylogenetic tree analysis of sea cucumber and other echinoderm RGP mature peptides based on maximum likelihood estimation (500 bootstraps). The echinoderm IGFs were used as the outgroup. The numbers above nodes indicate the branch support values. The scale bar indicates the estimated amino acid substitutions per site. For species abbreviations and sequences used in the amino acid alignment and phylogenetic tree, see Supplementary Data S1.

injection (Figure 6C), no animals displayed stress-induced evisceration (ejection of internal organs). Head waving was observed in animals injected with CS and HR at 30-60 min postinjection (Figure 6D, Supplementary Movie S1). At this time, the gonopore (Figure 6D, inset single arrow) located anteriorly and opposite the mouth position (Figure 6D, inset double arrow), was clearly visible. For CS, no animals spawned at $60 \mathrm{~min}$ but after 2 nd injection, spawning started at 90,120, and $180 \mathrm{~min}$ from time 0, respectively (Figure 6E). Spawning was completed within 60-80 min post-initiation. For $\mathrm{HR}$, only one injection was 


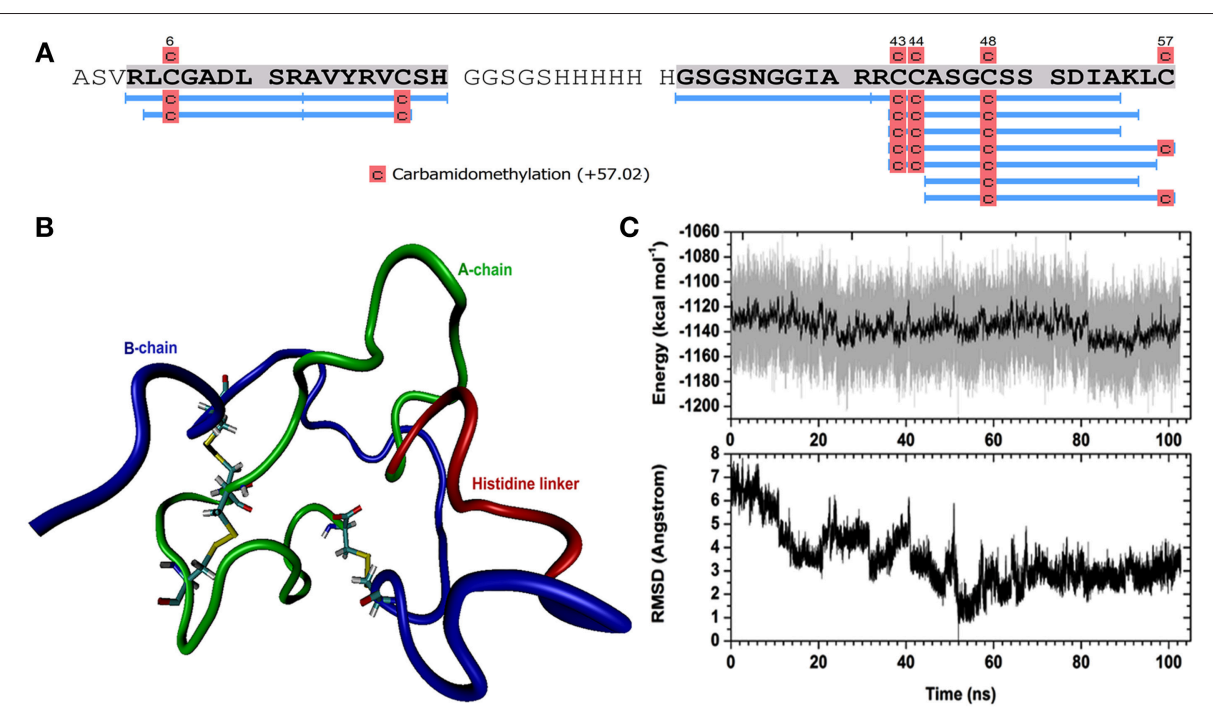

FIGURE 3 | Recombinant Holothuria scabra RGP and mass spectrometry (MS) identification. (A) RGP sequence showing MS peptide coverage (light blue lines). (B) A representative structure of recombinant RGP. Green: A-chain, dark blue: B-chain, red: histidine linker "GSGSHHHHHHGSGS". (C) Upper, potential energy of RGP peptide as a function of time during molecular dynamics (MD). Lower, backbone RMSD (root mean square deviation) during the same MD, compared to the lowest-energy conformation (the representative structure).

performed (at $40 \mu \mathrm{g}$ concentration) and spawning occurred at 90 , 120 , and $170 \mathrm{~min}$ from time 0 , respectively. All spawned eggs had undergone GVBD and were mature (Figure 6E, inset). Spawning was complete within 30-60 min post-initiation. For both negative controls, which were injected twice with either FASW or yeast solution, no head waving or spawning was observed.

Spawned oocytes were taken for fertilization with conspecific sperm, then cultured for larval and juvenile development (Figure 7, Table 3, Supplementary Movie S1). The development of embryos, larvae, and juveniles was asynchronous, with different stages and sizes observed simultaneously in culture. Fertilized eggs reached a size of $165-185 \mu \mathrm{m}$ prior to division into the 2-cell, 4-cell and multi-cellular stages (Figures 7A-D). Embryo size did not significantly change within the period of $1-8 \mathrm{~h}$ post-fertilization (hpf). The gastrula could be observed after 8-24 h post-fertilization and reached a size of $210-300 \mu \mathrm{m}$ (Table 3). At 1 day post-fertilization (dpf), the early auricularia stage was reached (ca. $300 \mu \mathrm{m}$ ) and then from 1 to $3 \mathrm{dpf}$ $(300-500 \mu \mathrm{m})$ the buccal ciliated cavity, cloaca and ossicle was observed (Figure 7E). At the mid-auricularia stage (39 dpf), larval size was notably increased, while the mouth and esophagus were additionally visible (Figure 7F). The lateauricularia, recognizable by the presence of a hyaline sphere, axohydrocoel, and left somatocoel, was observed at 10-16 dpf (Figure 7G) and the larvae were in the $900-1,200 \mu \mathrm{m}$ in size range. From then, the auricularia started decreasing in size $(500-800 \mu \mathrm{m})$ and subsequently transformed into the doliolaria stage (Figure $\mathbf{7 H}$ ). At this stage, primary tentacles primordium, digestive tract and ciliary band were observed. The pentactula was identified at $18 \mathrm{dpf}$, at which the ossicle, tentacles and podia were formed (Figure 7I). At the pentactula stage, larvae swam close to substrates and settled. Subsequently, podia developed in quantity along the ventral body wall and papillae on the dorsal body wall. Finally, pentactula transformed into juveniles and could be observed at $21 \mathrm{dpf}$. Juvenile reached a size of $4-5 \mathrm{~mm}$ by $36 \mathrm{dpf}$ (Table 3, Figure 7J).

\section{DISCUSSION}

The enhancement of aquaculture animal breeding using molecular approaches is now a common avenue for replacing or complementing traditional approaches. This includes the use of neuropeptide/hormone manipulation to enhance breeding strategies. However, this approach requires an indepth knowledge of the relevant molecular machinery. In sea stars, it is well-established that RGP plays an important role in oocyte maturation and spawning (Mita et al., 2009; Mita, $2013,2016)$ and we speculated that it could also play a similar role for sea cucumbers. In this study, we have produced a recombinant sea cucumber RGP using a yeast expression system and its bioactivity was confirmed through stimulation of oocyte maturation and spawning.

In the echinoderms, RGP was first characterized in Patiria pectinifera (called PpeRGP) and then identified in other sea star species, including Asterias amurensis RGP (AamRGP) and Aphelasterias japonica RGP (AjaRGP). The protein structure of AamRGP appears to be closer to AjaRGP than it is to PpeRGP (Mita, 2016). Cross-species in vitro oocyte maturation experiments showed that both AamRGP and AjaRGP could not induce oocyte maturation and ovulation in the ovary of $P$. pectinifera, although the PpeRGP was active in ovaries of A. amurensis and A. japonica (Mita, 2016). To further investigate the conservation of RGP in echinoderms, in this study we explored the holothurian RGP and performed sequence comparisons and phylogenetic analysis. The Holothuria RGP 
TABLE 2 | GVBD at $3 \mathrm{~h}$ post-incubation with test medium in Holothuria scabra and $H$. leucospilota.

\begin{tabular}{|c|c|c|c|}
\hline Tested medium & $\begin{array}{l}\text { Final peptide } \\
\text { concentration } \\
(\mu \mathrm{g} / \mu \mathrm{L})\end{array}$ & $\begin{array}{l}\text { H. scabra \% } \\
\text { GVBD }\end{array}$ & $\begin{array}{c}\text { H. leucospilota } \\
\% \text { GVBD }\end{array}$ \\
\hline \multirow[t]{3}{*}{ Crude supernatant (CS) } & 1.75 & $6.62 \pm 2.15$ & $0.34 \pm 0.06$ \\
\hline & 3.50 & $7.57^{\star} \pm 3.62$ & $1.39^{\star} \pm 0.86$ \\
\hline & 7.00 & $0^{\star \star}$ & $0^{\star \star}$ \\
\hline \multirow{3}{*}{$\begin{array}{l}\text { Crude concentrated RGP } \\
\text { (CR) }\end{array}$} & 28.25 & 0 & 0 \\
\hline & 56.50 & $0^{*}$ & $0^{*}$ \\
\hline & 113.00 & $0^{\star \star}$ & $0^{\star \star}$ \\
\hline \multirow[t]{3}{*}{ SepPak-purified RGP (SR) } & 24.00 & $2.45 \pm 1.70$ & $1.37 \pm 0.86$ \\
\hline & 48.00 & $65.23 \pm 14.58$ & $56.00 \pm 17.14$ \\
\hline & 96.00 & $99.42 \pm 0.37$ & $98.71 \pm 0.34$ \\
\hline \multirow{3}{*}{$\begin{array}{l}\text { His and Amicon-purified } \\
\text { RGP }(H R)\end{array}$} & 0.004 & $97.09 \pm 0.80$ & $86.29 \pm 2.62$ \\
\hline & 0.008 & $99.31 \pm 0.30$ & $89.15 \pm 1.76$ \\
\hline & 0.016 & $99.30 \pm 0.26$ & $93.26 \pm 1.82$ \\
\hline RNE $(0.2 \mu \mathrm{g} / \mu \mathrm{L})$ & 0.20 & $96.78 \pm 1.58$ & $96.67 \pm 3.76$ \\
\hline \multirow{3}{*}{$\begin{array}{l}\text { Yeast solution without } \\
\text { RGP (YS) }\end{array}$} & $0^{a}$ & $0.42 \pm 0.38$ & 0 \\
\hline & $0^{b}$ & $0^{\star}$ & $0^{\star \star}$ \\
\hline & $0^{c}$ & $0^{\star \star}$ & $0^{\star *}$ \\
\hline $\begin{array}{l}\text { Filtered artificial sea water } \\
\text { (FASW) }\end{array}$ & 0 & 0 & 0 \\
\hline
\end{tabular}

"Oocytes with partial distortion. " Oocytes with complete distortion. a20 $\mu \mathrm{l}$ YS and $60 \mu \mathrm{l}$ filtered artificial sea water (FASW). ${ }^{b} 40 \mu \mathrm{I}$ YS and $40 \mu \mathrm{l} \mathrm{FASW.}{ }^{c} 80 \mu \mathrm{l}$ YS in total.

showed highest homology to other echinoderm RGPs, with the highest conservation of amino acid composition found among the various Holothuria species ( $~ 87 \%)$, suggesting possible crossspecies bioactivity for RGP activity within Holothuria species, although further functional assays were required to confirm this. All RGPs contain 6 highly conserved cysteine residues, 4 and 2 of which are present in the A- and B-chains, respectively. This indicates a high selective pressure during the evolution of these critical cysteine residues, which are responsible for disulphide bridge formation. Despite the observed conservation within the A- and B-chains of echinoderm RGPs, the amino acid composition within the RGP-related peptide region was considerably variable. RGP belongs to the insulin/IGF/relaxin family, which include two sub-families such as insulin/IGF and RGP families (Wilkinson and Bathgate, 2007). Our alignment also showed conservation of amino acid composition, especially within the putative $\mathrm{A}$ - and $\mathrm{B}$-chain regions, among RGPs and IGFs in echinoderms. The major characteristics of RGP that are different to IGF include: (i) the conservation of a glycine residue prior to the third conserved cysteine residue with the A-chain of RGPs, but not IGFs; and (ii) an amino acid at the C-terminal end of the A-chain, which is the cysteine in RGPs but asparagine in IGFs. The phylogenetic analysis also confirmed a common root for these two peptide families. Within the RGP clades, two distinct sister clades were observed for RGPs from two different echinoderm classes, including the sea cucumber (holothuroids) RGPs and the sea star (asteroids) RGPs (see Figure 2B), which reflects the evolutionary divergence of this peptide during the evolution of echinoderms.
Following protein expression and purification, an average of $0.7 \mathrm{mg}$ pure RGP was obtained from $1 \mathrm{~L}$ of crude supernatant. This yield is comparable with previous studies, including the purification of FSH and $\mathrm{LH}$ recombinant proteins by using the same purification technique. For example, $0.4-0.9 \mathrm{mg} / \mathrm{L}$ recombinant yellowtail kingfish FSH (Sanchis-Benlloch et al., 2017) and $2.5 \mathrm{mg} / \mathrm{L}$ for the grouper FSH (Chen et al., 2012). Lower yields have been reported, such as $0.1 \mathrm{mg} / \mathrm{L}$ for the tilapia FSH (Aizen et al., 2007), $0.3 \mathrm{mg} / \mathrm{L}$ for the carp LH (HollanderCohen et al., 2017) and $0.08 \mathrm{mg} / \mathrm{L}$ for the tilapia $\mathrm{LH}$ (Kasuto and Levavi-Sivan, 2005). Generally, the yield was suggested to be varied depending on culture conditions (Yu et al., 2010) or the formation of dimeric forms (Aizen et al., 2007). The yield of the heterodimer was usually significantly lower than that of the monomer probably because of the complex structure of the former, for example, $6.5 \mathrm{mg} / \mathrm{L}$ were produced for the tilapia $\mathrm{FSH} \beta$ (monomer), while a yield of only $0.1 \mathrm{mg} / \mathrm{L}$ was obtained for the tilapia FSH $\beta \alpha$ (heterodimer) (Aizen et al., 2007). Production of the recombinant $H$. scabra RGP in the yeast expression system is an effective approach to obtain the copious amounts of RGP that would be required for commercial applications. However, the process of obtaining the slightly cheaper partially purified RGP and delivering to animals on a mass scale still requires optimisation and development of a method that is less laborious.

To confirm the successful production of the recombinant H. scabra RGP, in-solution digestion followed by LC-MS/MS was performed, which provided evidence of almost complete sequence coverage (see Figure 3A). The spectra additionally suggested the carbamidomethylation on four cysteines, which was potentially the result of reduction on cysteine residues and/or disulphide bridges. No other post-translational modifications were detected for the recombinant RGP. The MD simulation suggested the formation of three disulphide bonds and a disulphide bridge is formed within the A-chain. In terms of secondary structure, there was mainly turn and coil structures formed during the simulation, such as helix and $\beta$ sheet, which could also be seen from the RMSD calculation that shows significant fluctuation with respect to time. In conclusion, we found that the expression and purification of the recombinant RGP in our study was successful in term of quantity and a properly folded structure as confirmed by MD simulation. Therefore, this established RGP expression and purification procedures that could be applied and/or used as a fundamental procedure for RGP mass production for future uses.

In vitro and in vivo bioassays were used to assess the bioactivity and function of recombinant RGP in the sea cucumbers, $H$. scabra and $H$. leucospilota. The in vitro GVBD bioassay demonstrated that our recombinant RGP could induce GVBD, even at low concentrations (see Table 2). The recombinant $H$. scabra RGP peptide (SR, HR) could induce oocyte maturation/GVBD in both $H$. scabra and H. leucospilota, which is consistent with the conservation and similarity in the amino acids of RGP precursor (see Figure 2). Hence, a "generic" RGP recombinant may be employed to induce GVBD and spawning in more than one species of sea cucumber, although additional experiments showing compatibility of our RGP recombinant with other commercially important sea 

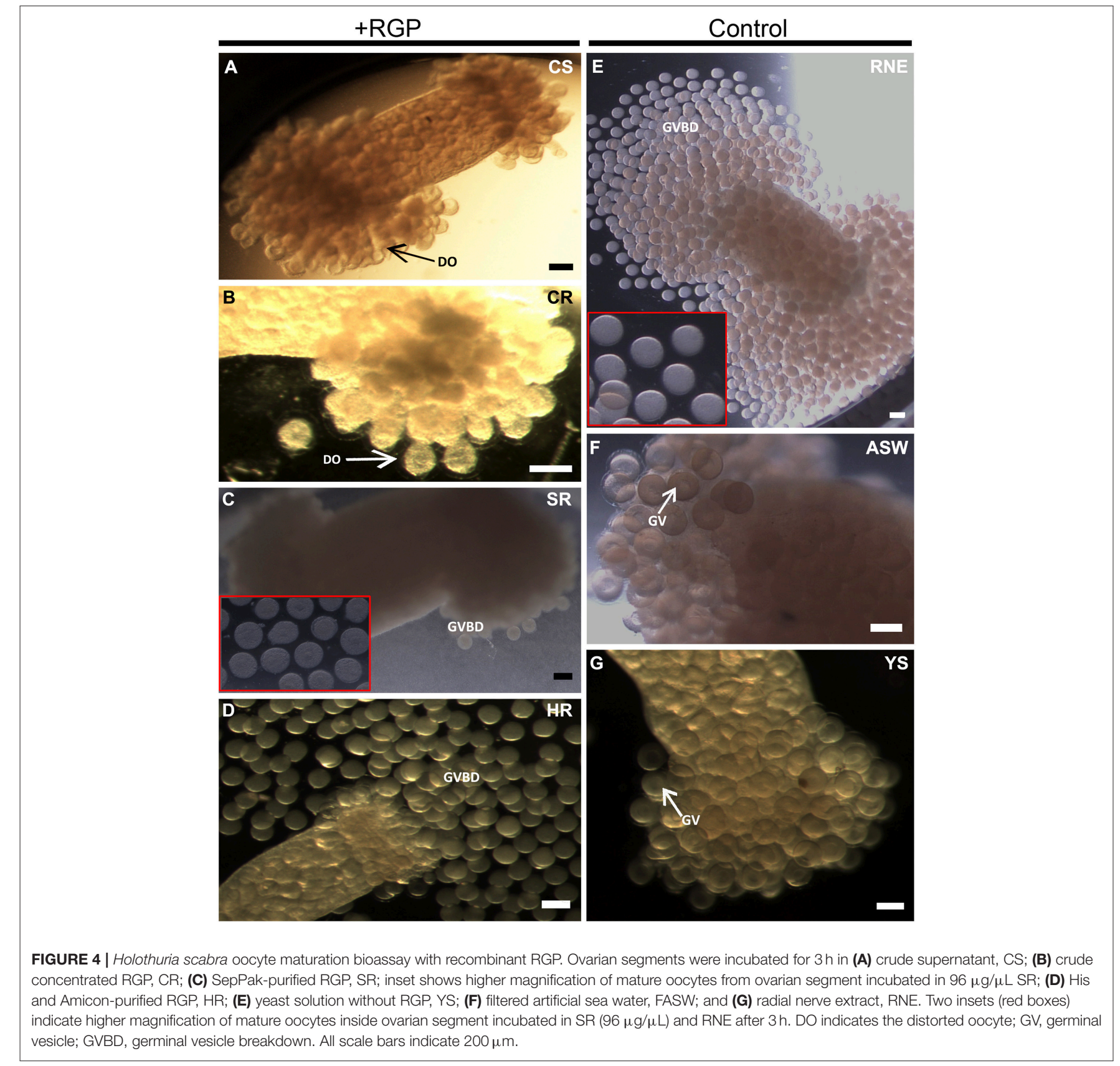

cucumber species should be verified in the future. Similarly in previous work, synthetically produced RGP could successfully induce GVBD in the sea stars Asterias aumerensis and Asterina pectinifera using in vitro bioassays (Kanatani et al., 1971; Mita, 1993). However, individual synthetic chains of RGP (either A- or B-chain) did not induce GVBD or spawning, whereas a synthetic heterodimeric form could induce GVBD and ovulation within $1 \mathrm{~h}$ of incubation in the Crown-of-Thorns sea star, Acanthaster planci (Mita et al., 2015). We found that partial GVBD and distortion of oocytes occurred when ovarian fragments were incubated with the crude supernatant CS and CR (see Table 2, Figure 4), which was likely due to a high salt concentration within these crude extracts. Meanwhile, a lower efficiency of GVBD was observed in the partially purified RGP (SR). Therefore, we suggest that it is essential to perform a complete or partial purification of the recombinant RGP before being employed as an oocyte maturation stimulant, in order to maximize the mature oocyte quality and quantity for further fertilization.

A recombinant RGP has advantages over the use of crude RNE, since it does not require the sacrifice of sea cucumbers, and the potential for other RNE factors that may stress the animals. Our bioassay experiments found that RGP stimulation of spawning did not cause evisceration or any observable stress to broodstock. In contrast, several traditional approaches in 


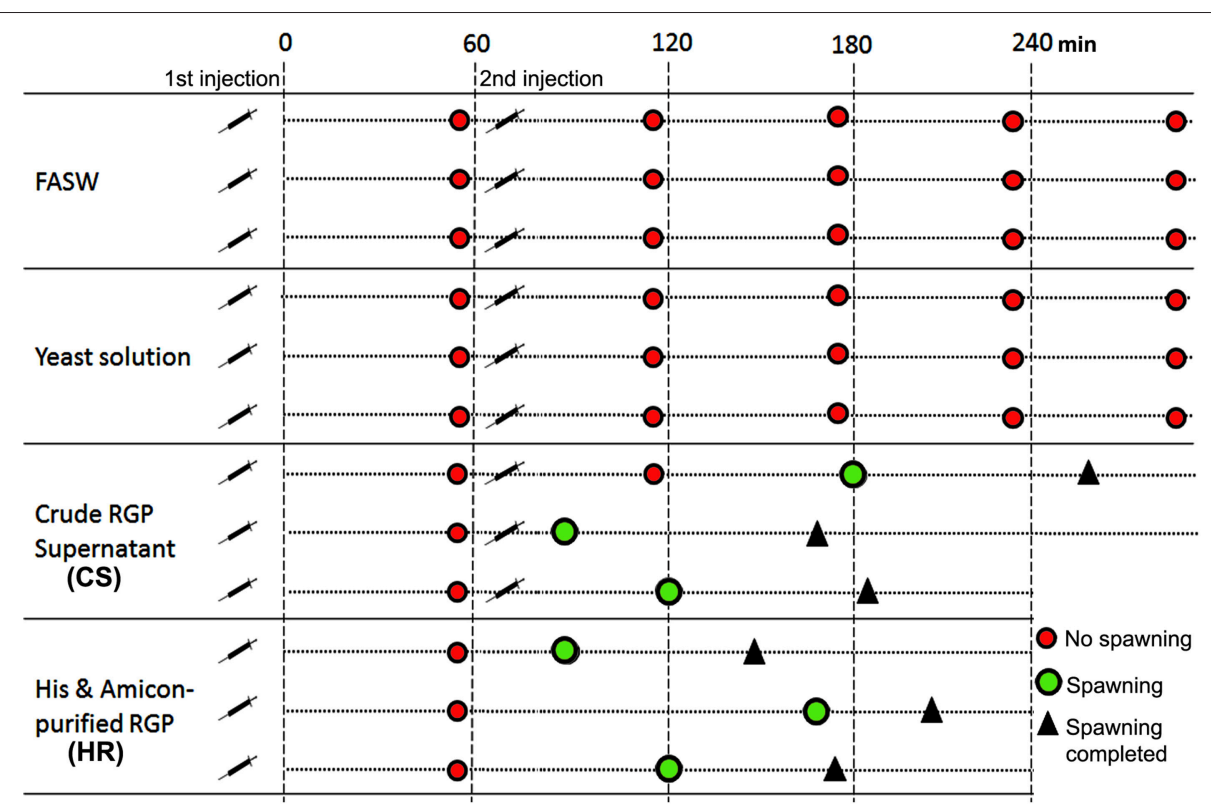

FIGURE 5 | Summary of Holothuria scabra spawning bioassay with recombinant RGP. Negative controls included filtered artificial seawater (FASW) and yeast solution without RGP. Test solutions included crude RGP supernatant (CS) and His and Amicon-purified RGP (HR). The first injection was a $2 \mathrm{~mL}$ volume and the second was a $3 \mathrm{~mL}$ volume.
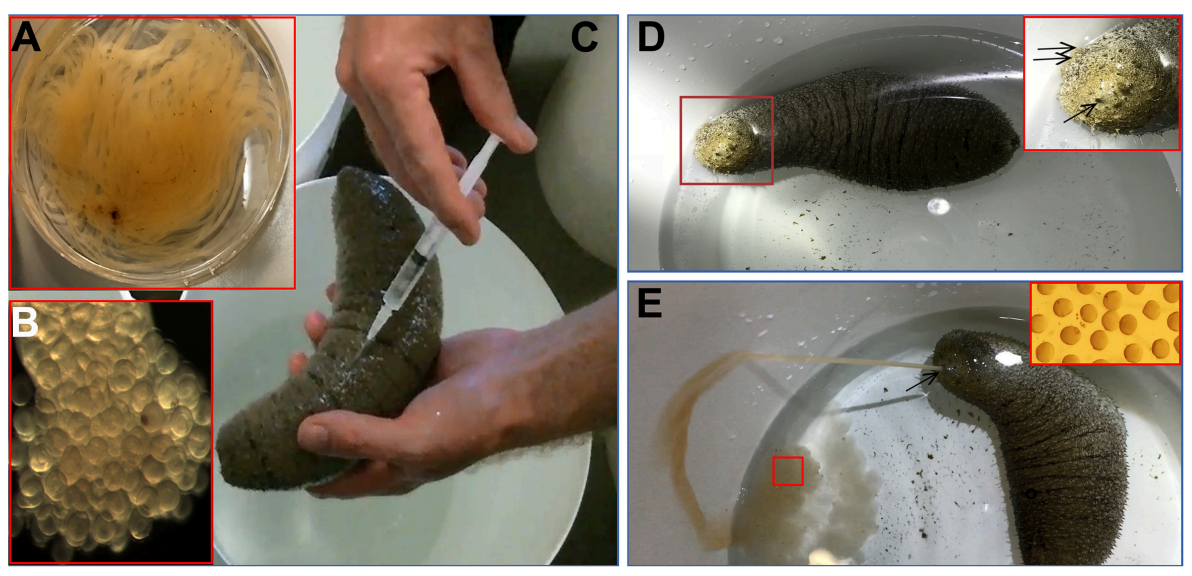

FIGURE 6 | Holothuria scabra spawning bioassay with recombinant RGP. (A) Total gonad from an individual showing tubules. (B) Immature oocytes (170 $\pm 6.4 \mu \mathrm{m}$ in diameter) with germinal vesicle before spawning. (C) Injection of sample into the body wall. (D) Head waving observed prior to spawning. Inset, higher magnification of sea cucumber head (red box), showing the location of gonopore (single arrow) and mouth (double arrow). (E) Sea cucumber spawning oocytes from gonopore. Inset, high magnification view of spawned oocytes (red box) indicating they were mature.

spawning stimulation [e.g., thermal shock, drying, and water pressure, sperm-induced spawning, dried alga spirulina bathing treatments (Battaglene et al., 2002; Al Rashdi et al., 2012)], could lead to significant animal stress. Another important factor that needs to be considered is the sea cucumber gonadosomatic growth peaks during the year (Battaglene et al., 2002). The traditional approaches usually require sea cucumbers at fully mature gonad stage (gonadal stage IV) for efficient spawning, but we showed in the current study that RGP could induce spawning as early as gonadal stage III (gonad weight 30-50 g and oocyte diameter $\geq 150 \mu \mathrm{m}$ ). The receptor for RGP still remains elusive, although in sea stars it has been recognized that the RGP is a ligand to a $G$ protein-coupled receptor that is expressed on follicle cells of growing to fully growing ovaries (stages III to V) (Mita et al., 2011a,b). Thus, we hypothesize that follicle cells and gonadal stages could affect RGP efficiency in sea cucumbers, depending on the presence of an RGP receptor.

In vivo spawning by injection of RGP in $H$. scabra was successfully achieved using pure RGP (HR), showing that the sea cucumbers exhibited the head waving characteristic at 3060 min post-injection, and subsequently spawned at either 90, 120 , or $170 \mathrm{~min}$ post-injection (see Figure 5). Furthermore, 

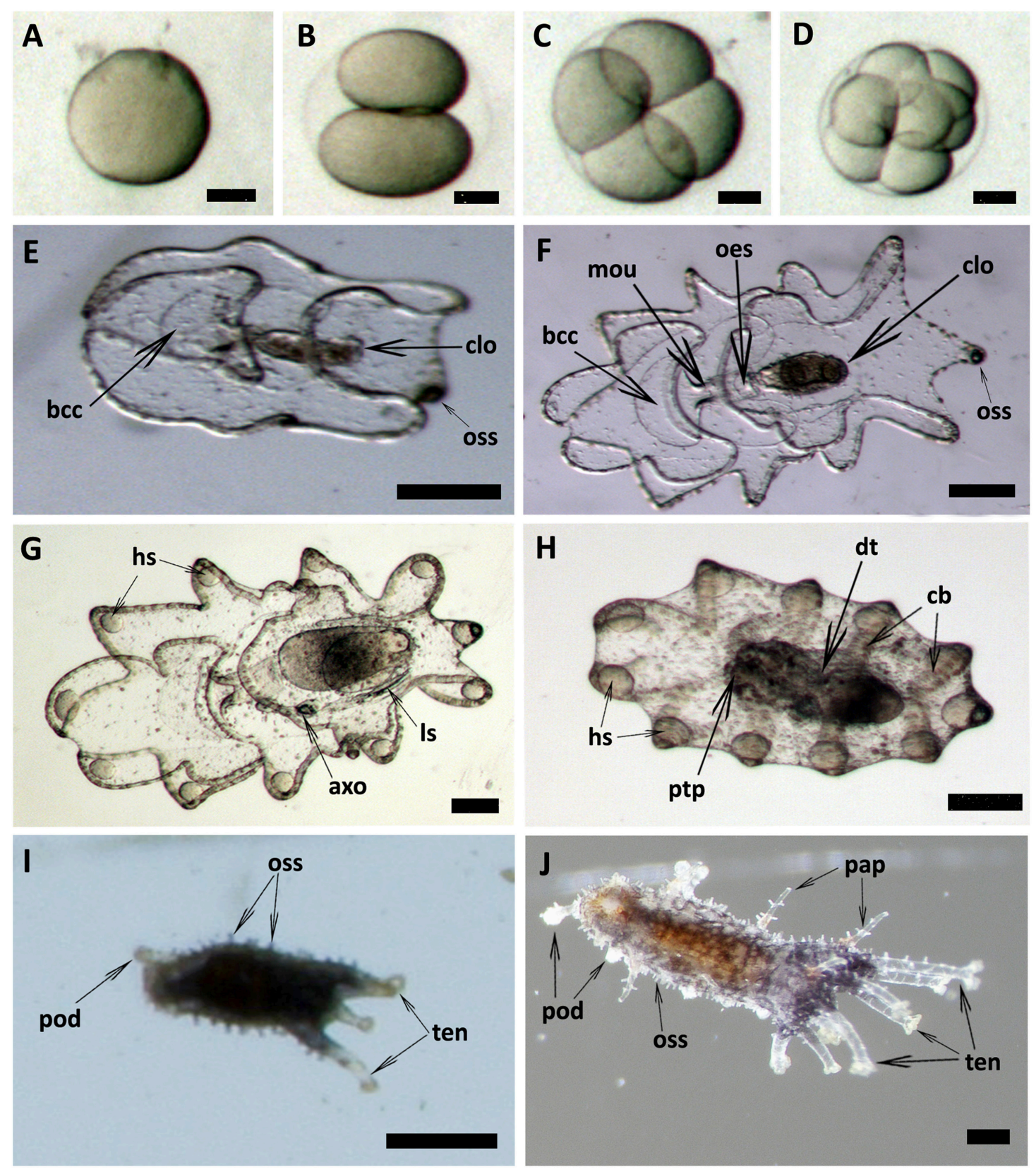

FIGURE 7 | Embryonic, larval development and juvenile growth of Holothuria scabra from RGP-matured eggs. (A) the matured eggs were fertilized, then (B-D) 2-cell, 4-cell and multi-cell division was occurred until $8 \mathrm{~h}$ post-fertilization. (E) early auricularia stage at 2 days post-fertilization (dpf). Buccal ciliated cavity (bcc), cloaca (clo), ossicle (oss). (F) Mid-auricularia stage at 5 dpf. Mouth (mou), oesophagus (oes). (G) Late-auricularia at 14 dpf. Hyaline sphere (hs), axohydrocoel (axo), left somatocoel (Is). (H) Doliolaria at 16-day; digestive tract (dt), ciliary band (cb), primary tentacles primordium (ptp). (I) Pentactula at 21 dpf. Tentacle (ten), podia (pod). (J) Juvenile at 36 dpf. Papillae (pap). Scale bars in (A-D) are $50 \mu \mathrm{m}$. Scale bars in (E-H) are $100 \mu \mathrm{m}$. Scale bars in (I,J) are $500 \mu \mathrm{m}$.

spawning was complete within 30-60 min with no subsequent additional spawning observed. This novel method is superior to other traditional stimulating methods since it does not require several days of pre-stimulation, such as thermal stimulation, prior to a spawning event. In addition, the use of RGP is a time and cost-effective procedure since it allows a rapid and highly controllable spawning event.

Injection with the unpurified crude RGP (CS) resulted in no spawning in the first $60 \mathrm{~min}$ post-injection, and as such a second injection was performed, leading to spawning within 30, 60 , or $120 \mathrm{~min}$ following the secondary injection. Spawning after the second injection was completed within 60-80 min. However, we observed that the animals did not show pre-spawning head waving behavior. Hence, we cannot preclude that stress induced spawning might occur when the animals were subjected to high concentration of RGP solution from 2 injections. These results support the observations from the GVBD in vitro assay in which the oocytes treated with high concentration of crude 
TABLE 3 | Summary of development in Holothuria scabra embryo, larvae and juvenile stages.

\begin{tabular}{lcc}
\hline Stages & Time & Size $(\boldsymbol{\mu} \mathbf{m})$ \\
\hline Fertilization & O min & $165-185$ \\
2-cell embryo & $50-70$ min & $165-185$ \\
4-cell embryo & $70-120$ min & $165-185$ \\
Multi-cell embryo & $2-8 \mathrm{~h}$ & $185-210$ \\
Gastrula & $8-24 \mathrm{~h}$ & $210-300$ \\
Early auricularia & $1-3 \mathrm{~d}$ & $300-500$ \\
Mid auricularia & $3-9 \mathrm{~d}$ & $500-900$ \\
Late auricularia & $10-16 \mathrm{~d}$ & $900-1,200$ \\
Dolillaria & $16-18 \mathrm{~d}$ & $500-800$ \\
Pentactula & $18-21 \mathrm{~d}$ & $750-1,100$ \\
Juvenile & $21-36 \mathrm{~d}$ & $1,100-4,500$ \\
\hline
\end{tabular}

RGP were deformed. Therefore, we suggest that not only purity but also the concentration of RGP is critical and are factors for maximum success for fertilization in artificial breeding of sea cucumbers. Further studies are required to determine the minimum recombinant RGP threshold/concentration for efficient spawning induction in the sea cucumbers.

In this study, we found that the development of the $H$. scabra larvae produced from RGP-induced spawning proceeded normally and was comparable to previous studies engaged the traditional spawning stimulations for fertilization and larval production (Battaglene et al., 1999; Mercier et al., 2000; Ivy and Giraspy, 2006; Al Rashdi et al., 2012; Ajith Kumara et al., 2013; Robinson et al., 2013; Abidin et al., 2016). For example, the pentacula stage larvae were predominant at $18-21 \mathrm{dpf}$ (see Table 3), which is similar to the previous reported durations of 13-26 dpf of metamorphosis to pentaculae (James, 2004; Dabbagh and Sedaghat, 2012; Mazlan and Hashim, 2015; Abidin et al., 2016). Furthermore, the larvae were reared through to their juvenile stage and appeared normal in their development. This result demonstrates that recombinant RGP for induced spawning is applicable in artificial breeding and that there are potential benefits for its use in sea cucumber hatcheries. However, the survival rates from fertilized oocytes, using the recombinant RGP, until the juvenile stages, need to be studied further.

\section{CONCLUSIONS}

This is the first study to demonstrate the production and use of a recombinant RGP in oocyte maturation and spawning induction in sea cucumbers. The outcome of this study provides a breakthrough new approach to artificial breeding in the sea cucumbers by using a recombinant RGP. We have developed the experimental procedures for the production of the recombinant RGP that could successfully induce in vitro oocyte maturation as well as spawning activity in sea cucumber broodstock. However, in order to help with hatchery production, further investigations are required in the future in order to obtain the optimal concentration and practicable delivery method. Furthermore, to understand the mechanism of RGP bioactivity in sea cucumbers, molecular signaling pathway analysis should be implemented. This information could help to overcome the seasonality requirements for RGP induced spawning.

\section{ETHICS STATEMENT}

The collection and handling of the animals in this study was carried out in accordance with the guidelines for the care and use of laboratory animals at the University of the Sunshine Coast, Australia.

\section{AUTHOR CONTRIBUTIONS}

SC and AE conceived the idea and provided oversight of the project from beginning to the final manuscript. HC carried out the laboratory components, in vitro and in vivo experiments and manuscript writing. LT carried out the in vivo spawning assay and was lead to the larvae and juvenile rearing at the Darwin Aquaculture Centre. MS, JN, and PP contributed to the subcloning, cloning, and all the steps in the laboratory production of the recombinant RGP. TW performed MS and molecular dynamic simulation. SS constructed sequence alignments and phylogeny analysis images. All authors provided critical feedback and contributed to the writing and review of the final manuscript.

\section{FUNDING}

This research was supported by USC-VIED $\mathrm{PhD}$ scholarship to $\mathrm{HC}$, which is funded by Ministry of Agriculture and Rural Development, Vietnam and USC, Australia. This research was undertaken with the assistance of resources from the National Computational Infrastructure (NCI), which is supported by the Australian Government.

\section{ACKNOWLEDGMENTS}

We gratefully acknowledge the financial support and laboratory facilities provided by the Genecology Research Centre, The Faculty of Science, Health, Education and Engineering and the Office of Research, University of the Sunshine Coast (USC) (807E9516), Australia. We also thank Tasmanian Seafoods P/L and Darwin Aquaculture Centre, Northern Territory for useful assistance in oocyte maturation and spawning bioassay.

\section{SUPPLEMENTARY MATERIAL}

The Supplementary Material for this article can be found online at: https://www.frontiersin.org/articles/10.3389/fgene. 2019.00077/full\#supplementary-material

Supplementary Data S1 | Amino acid sequences of relaxin/insulin-like peptides in echinoderms.

Supplementary Data S2 | Mass spectrometry (MS) data.

Supplementary Figure S1 | Antibiotic screening for high expression of RGP in yeast colonies.

Supplementary Movie S1 | A combinative movie of RGP injection, head waving behavior, spawning response, and larvae and juvenile development. 


\section{REFERENCES}

Abidin, N. A., Shaleh, S. R. M., Ching, F., Othman, R., Manjaji-Matsumoto, M., Senoo, S., et al. (2016). Egg and larval development of induced spawned sandfish (Holothuria scabra) in Hatchery. Int. J. Aqua. Sci. 7, 107-110.

Aizen, J., Chandler, J. C., Fitzgibbon, Q. P., Sagi, A., Battaglene, S. C., Elizur, A., et al. (2016). Production of recombinant insulin-like androgenic gland hormones from three decapod species: in vitro testicular phosphorylation and activation of a newly identified tyrosine kinase receptor from the Eastern spiny lobster, Sagmariasus verreauxi. Gen. Comp. Endocrinol. 229, 8-18. doi: 10.1016/j.ygcen.2016.02.013

Aizen, J., Kasuto, H., Golan, M., Zakay, H., and Levavi-Sivan, B. (2007). Tilapia Follicle-Stimulating Hormone (FSH): immunochemistry, stimulation by gonadotropin-releasing hormone, and effect of biologically active recombinant FSH on steroid secretion1. Biol. Reprod. 76, 692-700. doi: 10.1095/biolreprod.106.055822

Ajith Kumara, P. A. D., Jayanatha, J. S., Pushpakumara, J., Bandara, W., and Dissanayake, D. C. T. (2013). Artificial breeding and larval rearing of three tropical sea cucumber species - Holothuria scabra, Pseudocolochirus violaceus and Colochirus quadrangularis - in Sri Lanka. SPC Beche-de-mer Informat Bull. 13, 30-37.

Al Rashdi, K. M., Eeckhaut, I., and Claereboudt, M. R. (2012). A Manual on Hatchery of Sea Cucumber Holothuria scabra in the Sultanate of Oman. Muscat: Ministry of Agriculture and Fisheries Wealth; Aquaculture Centre.

Battaglene, S. C., Seymour, E. J., Ramofafia, C., and Lane, I. (2002). Spawning induction of three tropical sea cucumbers, Holothuria scabra, H. fuscogilva and Actinopyga mauritiana. Aquaculture 207, 29-47. doi: 10.1016/S0044-8486(01)00725-6

Battaglene, S. C., Seymour, J. E., and Ramofafia, C. (1999). Survival and growth of cultured juvenile sea cucumbers, Holothuria scabra. Aquaculture 178, 293-322. doi: 10.1016/S0044-8486(99)00130-1

Case, D. A., Babin, V., Berryman, J. T., Betz, R. M., Cai, Q., Cerutti, D. S., et al. (2014). AMBER 14. San Francisco, CA: University of California.

Chen, J., Zhang, Y., Tang, Z., Mao, J., Kuang, Z., Qin, C., et al. (2012). Production of recombinant orange-spotted grouper (Epinephelus coioides) follicle-stimulating hormone (FSH) in single-chain form and dimer form by Pichia pastoris and their biological activities. Gen. Comp. Endocrinol. 178, 237-249. doi: 10.1016/j.ygcen.2012.05.009

Chieu, H. D., Suwansa-Ard, S., Abramov, T., Elizur, A., and Cummins, S. F. (2018). In vitro oocyte maturation by radial nerve extract and early development of the black sea cucumber (Holothuria leucospilota). Aquaculture 495, 247-254. doi: 10.1016/j.aquaculture.2018.05.032

Dabbagh, A.-R., and Sedaghat, M. R. (2012). Breeding and rearing of the sea cucumber Holothuria scabra in Iran. SPC Beche-de-mer Inform. Bull. 32, 49-52.

Duan, Y., Wu, C., Chowdhury, S., Lee, M. C., Xiong, G., Zhang, W., et al. (2003). A point-charge force field for molecular mechanics simulations of proteins based on condensed-phase quantum mechanical calculations. J. Comput. Chem. 24, 1999-2012. doi: 10.1002/jcc.10349

Fahmy, S. R., Amer, M. A., and Al-Killidar, M. H. (2015). Ameliorative effect of the sea cucumber Holothuria arenicola extract against gastric ulcer in rats. J. Basic Appl. Zool. 72, 16-25. doi: 10.1016/j.jobaz.2015.03.001

Fujiwara, A., Yamano, K., Ohno, K., and Yoshikuni, M. (2010). Spawning induced by cubifrin in the Japanese common sea cucumber Apostichopus japonicus. Fish. Sci. 76, 795-801. doi: 10.1007/s12562-010-0262-2

Hayakawa, Y., Nagaya, H., Kaki, H., Hotta, K., and Kobayashi, M. (2008). Induction of spermatogenesis in Japanese eel by recombinant goldfish gonadotropins. Fish. Sci. 75, 137-144. doi: 10.1007/s12562-008-0007-7

Hollander-Cohen, L., Shpilman, M., and Levavi-Sivan, B. (2017). Biologically active recombinant carp $\mathrm{LH}$ as a spawning-inducing agent for carp. J. Endocrinol. 232, 391-402. doi: 10.1530/JOE-16-0435

Hollenberg, C. P., and Gellissen, G. (1997). Production of recombinant proteins by methylotrophic yeasts. Curr. Opin. Biotechnol. 8, 554-560.

Humphrey, W., Dalke, A., and Schulten, K. (1996). VMD: visual molecular dynamics. J. Mol. Graph 14, 27-38. doi: 10.1016/0263-7855(96)00018-5

Ivy, G., and Giraspy, D. A. B. (2006). Development of large-scale hatchery production techniques for the commercially important sea cucumber Holothuria scabra var. versicolor (Conand, 1986) in Queensland, Australia. SPC 28 Beche-de-mer Inform. Bull. 234, 28-34.
James, B. D. (2004). "Captive breeding of the sea cucumber, Holothuria scabra, from India," in Advances in sea cucumber Aquaculture and management, Vol. 463, eds A. Lovatelli, C. Conand, S. Purcell, S. Uthicke, J. F. Jamel, and A. Mercier (Rome: FAO), 385-395.

Kanatani, H., Ikegami, S., Shirai, H., Oide, H., and Tamura, S. (1971). Purification of gonad-stimulating substance obtained from radial nerves of the starfish, Asterias amurensis. Dev. Growth Differ. 13, 151-164. doi: 10.1111/j.1440-169X.1971.00151.x

Kasuto, H., and Levavi-Sivan, B. (2005). Production of biologically active tethered tilapia $\mathrm{LH} \beta \alpha$ by the methylotrophic yeast Pichia pastoris. Gen. Comp. Endocrinol. 140, 222-232. doi: 10.1016/j.ygcen.2004.10.016

Kato, S., Tsurumaru, S., Taga, M., Yamane, T., Shibata, Y., Ohno, K., et al. (2009). Neuronal peptides induce oocyte maturation and gamete spawning of sea cucumber, Apostichopus japonicus. Dev. Biol. 326, 169-176. doi: 10.1016/j.ydbio.2008.11.003

Katow, H., Katow, T., and Moriyama, A. (2009). Gonad-stimulating substancelike molecule from the radial nerve of the Sea cucumber. Int. J. Dev. Biol. 53, 483-491. doi: 10.1387/ijdb.082801hk

Kumar, S., Stecher, G., and Tamura, K. (2016). MEGA7: molecular evolutionary genetics analysis version 7.0 for bigger datasets. Mol. Biol. Evol. 33, 1870-1874. doi: 10.1093/molbev/msw054

Leonet, A., Rasolofonirina, R., Wattiez, R., Jangoux, M., and Eeckhaut, I. (2009). A new method to induce oocyte maturation in holothuroids (Echinodermata). Inverteb. Reprod. Dev. 53, 13-21. doi: 10.1080/07924259.2009.9652285

Lovatelli, A. (2004). Advances in Sea Cucumber Aquaculture and Management. Rome, FAO.

Madden, K., Tolstorukov, I., and Cregg, J. (2015). "Electroporation of Pichia pastorism," in Genetic Transformation Systems in Fungi, Vol 1. Fungal Biology (Cham: Springer), 87-91. doi: 10.1007/978-3-319-10142-2_8

Maruyama, Y. K. (1980). Artificial induction of oocyte maturation and development in the sea cucumbers Holothuria leucospilota and Holothuria pardalis. Biol. Bull. 158, 339-348. doi: 10.2307/1540860

Maruyama, Y. K. (1985). Holothurian Oocyte Maturation Induced by Radial Nerve. Biol. Bull. 168, 249-262. doi: 10.2307/1541238

Mazlan, N., and Hashim, R. (2015). Spawning induction and larval rearing of the sea cucumber Holothuria scabra in Malaysia. SPC Beche-de-mer Inform. Bull. 35, 32-36.

Mercier, A., Battaglene, S. C., and Hamela, J. F. (2000). Settlement preferences and early migration of the tropical sea cucumber Holothuria scabra. J. Exp. Mar. Biol. Ecol. 249, 89-110. doi: 10.1016/S0022-0981(00)00187-8

Mercier, A., Sims, D., and Hamel, J. F. (2009). Endogenous and exogenous control of gametogenesis and spawning in echinoderms. Adv. Mar. Biol. 55, 1-302. doi: 10.1016/S0065-2881(09)55001-8

Mita, M. (1993). 1-Methyladenine production by ovarian follicle cells responsible for spawning in the starfish Asterina pectinifera. Inverteb Reprod. Dev. 24, 237-242. doi: 10.1080/07924259.1993.9672357

Mita, M. (2013). Relaxin-like gonad-stimulating substance in an echinoderm, the starfish: a novel relaxin system in reproduction of invertebrates. Gen. Comp. Endocrinol. 181, 241-245. doi: 10.1016/j.ygcen.2012. 07.015

Mita, M. (2016). Starfish gonadotropic hormone: relaxin-like gonadstimulating peptides. Gen. Comp. Endocrinol. 230-231, 166-169. doi: 10.1016/j.ygcen.2016.04.016

Mita, M., Ikeda, N., Haraguchi, S., Tsutsui, K., Nakano, Y., and Nakamura, M. (2015). A gonad-stimulating peptide of the crown-of-thorns starfish, Acanthaster planci. Inverteb. Reprod. Dev. 59, 212-217. doi: 10.1080/07924259.2015.1086828

Mita, M., Yamamoto, K., and Nagahama, Y. (2011a). Interaction of Relaxinlike Gonad-stimulating Substance with Ovarian Follicle Cells of the Starfish Asterina pectinifera. Zool. Sci. 28, 764-769. doi: 10.2108/zsj.28.764

Mita, M., Yamamoto, K., Nakamura, M., and Nagahama, Y. (2011b). Hormonal action of relaxin-like gonad-stimulating substance (GSS) on starfish ovaries in growing and fully grown states. Gen. Comp. Endocrinol. 172, 85-89. doi: 10.1016/j.ygcen.2011.01.014

Mita, M., Yoshikuni, M., Ohno, K., Shibata, Y., Paul-Prasanth, B., Pitchayawasin, S., et al. (2009). A relaxin-like peptide purified from radial nerves induces oocyte maturation and ovulation in the starfish, Asterina pectinifera. Proc. Natl. Acad. Sci. U.S.A. 106, 9507-9512. doi: 10.1073/pnas.0900243106 
Ni, G., Liang, D., Cummins, S. F., Walton, S. F., Chen, S., Wang, Y., et al. (2018). Comparative proteomic study of the antiproliferative activity of frog host-defence peptide caerin 1.9 and its additive effect with caerin 1.1 on TC1 cells transformed with HPV16 E6 and E7. Biomed. Res. Int. 2018:7382351. doi: $10.1155 / 2018 / 7382351$

Olivera-Castillo, L., Davalos, A., Grant, G., Valadez-Gonzalez, N., Montero, J., Barrera-Perez, H., et al. (2013). Diets containing sea cucumber (Isostichopus badionotus) meals are hypocholesterolemic in young rats. PLoS ONE 8:e79446. doi: 10.1371/journal.pone.0079446

Petersen, T. N., Brunak, S., Von Heijne, G., and Nielsen, H. (2011). SignalP 4.0: discriminating signal peptides from transmembrane regions. Nat. Methods 8, 785-786. doi: 10.1038/nmeth.1701

Purcell, S. W., Mercier, A., Conand, C., Hamel, J.-F., Toral-Granda, M. V., Lovatelli, A., et al. (2011). Sea cucumber fisheries: global analysis of stocks, management measures and drivers of overfishing. Fish Fish. 14, 34-59. doi: 10.1111/j.1467-2979.2011.00443.x

Robinson, G., Slater, M. J., Jones, C. L. W., and Stead, S. M. (2013). Role of sand as substrate and dietary component for juvenile sea cucumber Holothuria scabra. Aquaculture 392-395, 23-25. doi: 10.1016/j.aquaculture.2013.01.036

Sanchis-Benlloch, P. J., Nocillado, J., Ladisa, C., Aizen, J., Miller, A., Shpilman, M., et al. (2017). In-vitro and in-vivo biological activity of recombinant yellowtail kingfish (Seriola lalandi) follicle stimulating hormone. Gen. Comp. Endocrinol. 241, 41-49. doi: 10.1016/j.ygcen.2016.03.001

Smiley, S. (1990). A review of echinoderm oogenesis. J. Electron Microsc. Tech. 16, 93-114. doi: 10.1002/jemt.1060160203

Southey, B. R., Amare, A., Zimmerman, T. A., Rodriguez-Zas, S. L., and Sweedler, J. V. (2006). NeuroPred: a tool to predict cleavage sites in neuropeptide precursors and provide the masses of the resulting peptides. Nucleic Acids Res. 34, W267-W272. doi: 10.1093/nar/gkl161

Suwansa-ard, S., Chaiyamoon, A., Talarovicova, A., Tinikul, R., Tinikul, Y., Poomtong, T., et al. (2018). Transcriptomic discovery and comparative analysis of neuropeptide precursors in sea cucumbers (Holothuroidea). Peptides 99, 231-240. doi: 10.1016/j.peptides.2017.10.008

Tiu, S. H., and Chan, S. M. (2007). The use of recombinant protein and RNA interference approaches to study the reproductive functions of a gonadstimulating hormone from the shrimp Metapenaeus ensis. FEBS J. 274, 4385-4395. doi: 10.1111/j.1742-4658.2007.05968.x

Weinacker, D., Rabert, C., Zepeda, A. B., Figueroa, C. A., Pessoa, A., and Farías, J. G. (2013). Applications of recombinant Pichia pastoris in the healthcare industry. Brazil. J. Microbiol. 44, 1043-1048.

Wilkinson, T. N., and Bathgate, R. A. D. (2007). The evolution of the relaxin peptide family and their receptors. Relaxin Related Peptides 612, 1-13. doi: 10.1007/978-0-387-74672-2_1

Yamano, K., Fujiwara, A., Nakamura, A., and Yoshikuni, M. (2013). In vitro induction of oocyte maturation in the Japanese sea cucumber Apostichopus japonicus by cubifrin and the developmental ability of the eggs. Fish. Sci. 79, 823-832. doi: 10.1007/s12562-013-0665-y

Yu, X., Lin, S. W., Kobayashi, M., and Ge, W. (2010). Expression of recombinant zebrafish follicle-stimulating hormone (FSH) in methylotropic yeast Pichia pastoris. Fish Physiol. Biochem. 36, 273-281. doi: 10.1007/s10695-008-9244-Z

Conflict of Interest Statement: The authors declare that the research was conducted in the absence of any commercial or financial relationships that could be construed as a potential conflict of interest.

Copyright (c) 2019 Chieu, Turner, Smith, Wang, Nocillado, Palma, Suwansa-ard, Elizur and Cummins. This is an open-access article distributed under the terms of the Creative Commons Attribution License (CC BY). The use, distribution or reproduction in other forums is permitted, provided the original author(s) and the copyright owner(s) are credited and that the original publication in this journal is cited, in accordance with accepted academic practice. No use, distribution or reproduction is permitted which does not comply with these terms. 